\title{
A DINÂMICA TERRITORIAL DOS POVOADOS SANTO ANTÔNIO I E II EM BARRA DO CHOÇA-BAHIA
}

The territorial dynamics of the towns of Santo Antônio I and II in Barra do Choça-Bahia

\author{
La dinámica territorial de los pueblos Santo Antônio I y II an Barra do Choça-Bahia
}

Geisa Alves dos Santos ${ }^{1}$

Greiziene Araújo Queiroz ${ }^{2}$

\footnotetext{
${ }^{1}$ Graduada em Geografia pela Universidade Estadual do Sudoete da Bahia - UESB, email - geisaalves115@ gmail.com

${ }^{2}$ Professor (a) Substituto do Departamento de Gografia da Universidade Estadual do Sudoete da Bahia - UESB, email greiziene@gmail.com
}

\begin{abstract}
Resumo
O objetivo dessa pesquisa é analisar a dinâmica territorial dos povoados Santo Antônio I e II, no município de Barra do Choça-BA. Para alcançar esse objetivo foi necessário: identificar os eventos históricos que originaram o território; Caracterizar a dinâmica populacional e os fluxos e os movimentos migratórios; Verificar as atividades econômicas que engloba o setor primário e terciário; Compreender os aspectos que qualificam condições de vida da população. Dentre os elementos estudados o fator que mais confere dinamicidade ao território é a cafeicultura. Este estudo apresentou dois povoados em suas formas e conteúdos, articulados pela dinâmica do território. Quando os homens agem sobre o território e dele se apropriam conferem vida aquela fração do espaço e faz dele seu abrigo.
\end{abstract}

Palavras-chave: Território; dinâmica; migração.

\begin{abstract}
The objective of this research is to analyze the territorial dynamics of the settlements Santo Antônio I and II, in the municipality of Barra do Choça-BA. To achieve this goal it was necessary to: identify the historical events that originated the territory; Characterize population dynamics and migratory flows and movements; To verify the economic activities that comprise the primary and tertiary sector; Understand the aspects that qualify living conditions of the population. Among the studied elements, the factor that most confers dynamicity to the territory is coffee cultivation. This study presented two settlements in their forms and contents, articulated by the dynamics of the territory. When men act on and take possession of the territory they bring life to that fraction of space and make it their home.
\end{abstract}

Keywords: Territory; dynamics; migration.

\section{Resumen}

El objetivo de esta investigación es analizar la dinámica territorial de los poblados Santo Antônio I y II, en el municipio de Barra do Choça-BA. Para alcanzar ese objetivo fue necesario: identificar los eventos históricos que originaron el territorio; Caracterizar la dinámica poblacional y los flujos y los movimientos migratorios; Verificar las actividades económicas que engloban el sector primario y terciario; Comprender los aspectos que califica las condiciones de vida de la población. Entre los elementos estudiados el factor que más confiere dinamicidad al territorio es la cafeicultura. Este estudio presentó dos poblados en sus formas y contenidos, articulados por la dinámica del territorio. Cuando los hombres actúan sobre el territorio y de él se apropian, confieren vida aquella fracción del espacio y lo hace su abrigo.

Palabras clave: Territorio; dinâmica; migración. 


\section{Introdução}

Embora o Brasil seja um país mais urbano, em termos populacionais, que rural e o urbano apareça com maior dinamicidade por concentrar mais objetos técnicos e mais ações engendradas em sistemas, cada subespaço rural possui uma dinâmica peculiar. A partir dessa premissa tomamos como recorte empírico os Povoados Santo Antônio I e II, localizado na zona rural do município de Barra do Choça no interior da Bahia.

A dinâmica territorial do povoado em tela foi analisada por meio da: (i) identificação dos eventos históricos que deram origem a formação territorial do município e consequentemente dos povoados; (ii) caracterização dos fluxos populacionais (iii) e constatação das atividades econômica presente no povoados bem como os aspectos que qualificam condições de vida da população tais como: moradia, emprengo, renda, saúde e educação.

Por muito tempo as pesquisas, na Geografia, relegou a um segundo plano os estudos de localidades de pequenas dimensões como vilas, distritos e povoados. No entanto, com as mudanças ocorridas nas últimas décadas urge a necessidade de se comtemplar todo o espaço geográfico sem qualificá-lo como de maior ou menor importância. Afinal, os "tentáculos" da globalização alcancam todas as escalas e todos os agentes e as mudanças são perceptíveis. Está em curso um processo de ressignificação do rural, mediante a reestruturação das forças produtivas e do modo de vida.

A metodologia utilizada consiste no levantamento de dados primários: trabalho de campo, observação direta, conversas informais, entrevistas, aplicação de questionários e registros fotográficos. Para os dados secundários optou-se por pesquisas no SEI e IBGE.

\section{Território e Formação territorial: Um breve histórico}

O Território como conceito geográfico caminha por diferentes vertentes analíticas. Essa pesquisa analisa não o território em si como fração de solo, mas os usos sociais do mesmo. Para Santos "É o uso do território [...] que faz dele objeto da análise social" (1994, p.255). O uso produz movimentos de toda natureza assim, enquanto 
"alguns se fixam no território, outros se movem constantemente, de acordo com o grau de competitividade e de resistência às dinâmicas" (VALVERDE, 2004, p. 125).

A dinâmica territorial, isto é, o movimento que se dá no território por meio dos usos carrega consigo uma herança histórica que se tornal fundamental para o entendimento do presente. A história de Barra do Choça está imbricada com o antigo sertão da ressaca, atualmente denominado de Planalto da Conquista. O povoamento se acentuou em meados do século XVIII a partir da chegada de tropeiros viajantes e criadores de gado e foi se consolidando nos séculos seguintes. Em meados de 1950 a Vila da Barra, pertencente ao município de Vitória da Conquista, foi elevada a categoria de distrito, essa condição distrital permaneceu até o dia 22 de junho de 1962 quando foi decretado o desmembramento "configurando-se assim, em um município pela Lei Estadual no. 1.694, de 22 de junho de 1962 e instalado em 07 de abril de 1963”. (GOMES, 2008, p. 54)

Figura 1- Mapa de localização dos Povoados Santo Antônio I e II no munícipio de Barra do Choça-BA.

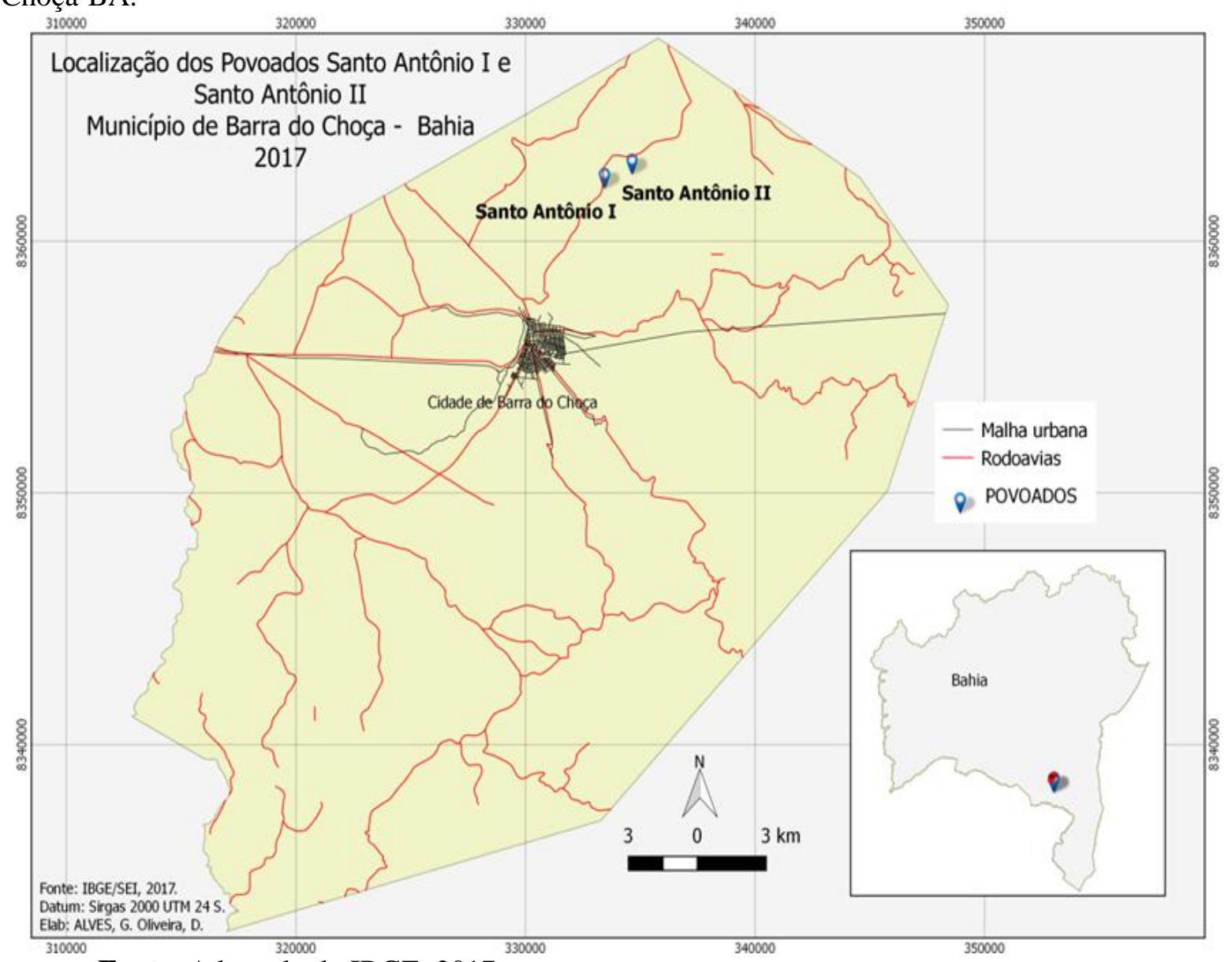

Fonte: Adaptado do IBGE, 2017. 
A formação do povoado Santo Antônio se origina da Fazenda Rio dos Porcos. Na década de 1960 um latifuindiário doou e vendeu boa parte da terra para pessoas conhecidas e funcionários de sua fazenda. Essas "doações" eram concedidas aos trabalhadores como forma de pagamento dos anos de serviço prestado. Com a chegada dos primeiros moradores e suas famílias, a localidade foi crescendo e em meados de 1973 se configurou como povoado dos Porcos I. Segundo os moradores, a origem do nome é devido ao um antigo rio que passava no local, nesse período também predominava a criação de porcos o que originou os nomes Porcos I e Porcos II, décadas depois culmina nos povoados Santo Antônio I e II conforme o mapa de localização.

Essa transição de nomenclatura dos povoados de Porcos para Santo Antônio se deu após o asfaltamento da estrada que corta os povoados e os conceta ao município de Planalto. Essa mudança ocorreu em comum acordo com a população de predominância de católica. No povovoado I encontra-se a igreja, fundada há 40 anos, em homenagem ao padroeiro Santo Antônio.

A abertura e venda de lotes para construção de moradias permitiu o maior adensamento populacional no Povoado Santo Antônio II, já que os lotes eram menores e com maior proximidade, configurando arruamentos que se assemelham ao sistema urbano ortogonal.

Atualmente os Povoados Santo Antônio I e II, apresentam configurações espaciais diferentes de sua origem, devido à expansão territorial e populacional, inserção da cafeicultura e as mudanças ocorridas no meio rural nas últimas décadas que influenciaram no modo de vida. Dessa maneira os povoados ganharam visibilidade, firmando relações com a cidade e localidades próximas. Essa historicidade é basilar para o presente estudo, pois, entende-se que a formação territorial do município de Barra do choça-Bahia é intreseco a formação dos povoados Santo Antônio I e II objetos dessa pesquisa.

\section{Dinâmica populacional}

Sabe-se que o movimento migratório não é fenômeno recente, ele faz parte da história da humanidade desde os primórdios, onde os nômades se deslocavam em busca de necessidades básicas de sobrevivência. Isso permitiu a ocupação do território em várias extensões da terra. ${ }^{3}$ No caso brasileiro, o movimento migratório ocorre em várias esferas do território, sejam internas, externas (intraregional, estadual).

\footnotetext{
${ }^{3}$ Conforme DAMIANI, Amélia. Geografia e população. São Paulo: Editora contexto, p.60-65, 2002.
} 
Predominantemente por razões econômicas e/ou climáticas. A primeira é motivada pelo desemprego com vistas de melhorar as condições sociais e materias. A segunda é um fator natural, normalmente devido a fortes secas.

Entende-se que a migração é todo deslocamento de pessoas que decidem sair do seu lugar de origem para outro lugar. Esse movimento migratório compreendem a história do munícipio de Barra do Choça e consequentemente nos Povoados Santo Antônio I e II formados originalmente a partir do descolamento populacional para este território em estudo. "Na década de 1960 a estrutura urbana de Barra do Choça ainda era muito rudimentar com uma população que não ultrapassava 1.000 habitantes" (ROCHA e SANTOS, 2015, p.12).

Tabela 01. População de Barra do Choça, por situação domiciliar de 1970 a 2010.

\begin{tabular}{c|c|c|c|c|c}
\hline \multicolumn{6}{c}{ Ano } \\
\hline $\begin{array}{c}\text { Situação do } \\
\text { domicílio }\end{array}$ & $\mathbf{1 9 7 0}$ & $\mathbf{1 9 8 0}$ & $\mathbf{1 9 9 1}$ & $\mathbf{2 0 0 0}$ & $\mathbf{2 0 1 0}$ \\
\hline Total & 8.904 & 20.524 & 24.844 & 40.818 & 34.788 \\
\hline Urbana & 1.445 & 6.484 & 11.644 & 17.721 & 22.407 \\
\hline Rural & 7.459 & 14.040 & 13.200 & 23.097 & 12.381 \\
\hline
\end{tabular}

Fonte: Censos do IBGE - 1970, 1980, 1991, 2000 e 2010. Adaptado por (ROCHA, 2015)

Conforme a tabela nos anos de 1980 o crescimento da população urbana passa a ser mais significativo.

Os dados do Censo de 1970 aponta que $83,7 \%$ da população residiam na zona rural, e manteve predominando, conforme a tabela 01 , até os anos 2000, com 56,58\%. Somente em 2010 é que a população urbana chega a $63 \%$ e ultrapassa a população rural. De acordo com os Censos Demográficos do IBGE é possível verificar que existe um decréscimo da população rural no município de Barra do Choça nos últimos dez anos.( ROCHA e SANTOS, 2015, p.12).

O aumento da população residente nas zonas urbanas é crescente. Acreditamos que esse crescimento tem como fator preponderante a inserção do município no circuito produtivo do café que promoveu alterações no campo e na cidade.

\section{Os fluxos migratórios nos povoados de Santo Antônio I e II}

Conforme relatos de moradores antigos o Povoado de Santo Antônio I se formou com a chegada de dois migrantes: O senhor Aristides migrante de Montes Claros localizado no norte de Minas Gerais e o Sr. José Carlos migrante de Gameleira do Machado, Zona Rural de Aracatu no sertão baiano. 
Não há uma datação cronológica para estes fatos, mas conforme a moradora Ivani Andrade, filha de Aristides "quando ele chegou aqui, ele disse que a Barra tinha apenas uma rua, ele veio pra cá pra trabalhar numa fazenda e construiu a primeira casa" (Informação verbal, 2016). Com base nesse relato, compreende-se que a história dos povoados está intrinsecamente ligada com a estruturação da cidade de Barra do Choça. Ainda segundo D. Ivani, as terras eram devolutas (pertencentes ao estado) ou seja, não tinha "dono" quem chegava se apossava.

O Fluxo migratório despontou em 1939 com a chegada de Ramiro Barbosa vindo de Bom Jesus da Serra-BA. Conforme o relato de seu filho Joaquim Moura, seu pai e sua mãe Milú fugiram da seca e decidiu fixar sua moradia no lugar devido a abundância de recursos hídricos.

Quando meu pai Ramiro chegou aqui em 1939, já morava Zé Carlos, Joaquim Cascaes e Aristides, meu pai falava que saiu do sertão de Bom Jesus(da Serra) para vim pra cá por causa da seca, lá faltava água, não chovia muito e os rios tava tudo seco, saiu de lá a procura de um lugar que tivesse água e terra pra plantar, parou aqui e ficou(Informação Verbal, 2016) .

Nesse mesmo contexto chegaram famílias do sertão conquistense Sr. Filoteus Lopes, Otaviano, Antônio, Ana e a família Cortes e Bom Jesus da Serra (Sr. Ramiro).

Afirma-se que geralmente o interesse dos migrantes sobre este território se dava pelas condições climáticas, pois a localidade era vista como terra fértil e produtiva, justificado pela localização na zona da mata que tem como característica longos períodos de chuva, esses migrantes com o intuito de plantar para sobreviver, já que a terra era fértil como afirma à moradora Elenita Leite:

Meu pai contava que veio pra cá por causa da chuva, a gente veio do sertão, lá a seca castigava, não tinha como plantar, a vida lá era difícil, família grande e não tinha como sobreviver, quando chegamos aqui era diferente, chovia muito, começamos a plantar, a chuva era abençoada, tudo que plantava dava, era uma terra muito boa, quando chegamos aqui a fartura começou, construímos nossa casa e daqui não sair." (Informação Verbal, 2016) ${ }^{5}$.

Além desses grupos de migrantes que fixaram morada na localidade e multiplicaram suas famílias, verificou-se no Povoado Santo Antônio I fluxos migratórios interestaduais, esses fluxos entre os estados começou a partir do primeiro migrante de Minas Gerais e nos anos de 2000 um grupo de familiares oriundos do

\footnotetext{
${ }^{4}$ Entrevista concedida por Joaquim Moura. Entrevista1 [2016]. Entrevistador: Geisa Alves dos Santos. Povoado de Santo Antonio-Barra do Choça-Ba, 2016. 1 arquivo .mp3 (20 min.).

${ }^{5}$ Entrevista concedida por Elenita Leite. Entrevista2 [2016]. Entrevistador: Geisa Alves dos Santos. Povoado de Santo Antonio-Barra do Choça-Ba, 2016. 1 arquivo .mp3 (20 min.).
} 
estado de Pernambuco fixaram residência na localidade reafirmando o interesse pela terra produtiva.

A partir daí várias famílias foram se fixando no Pov. II em razão da proximidade das grandes fazendas de café no entorno. Outro fator atrativo era o baixo valor dos terrenos, por isso, muitas famílias de localidades rurais mais próximas migraram para o povoado, estes têm como origem: Planalto, Poções, Vitória da Conquista, Caatiba e Anagé; Verificou-se também a existência de migrantes de municípios mais distantes localizados no sul da Bahia como: Itamaraju e Itabuna.

Figura 02 - Gráfico com os dados do lugar de Origem dos Moradores do Povoado Santo Antônio II.

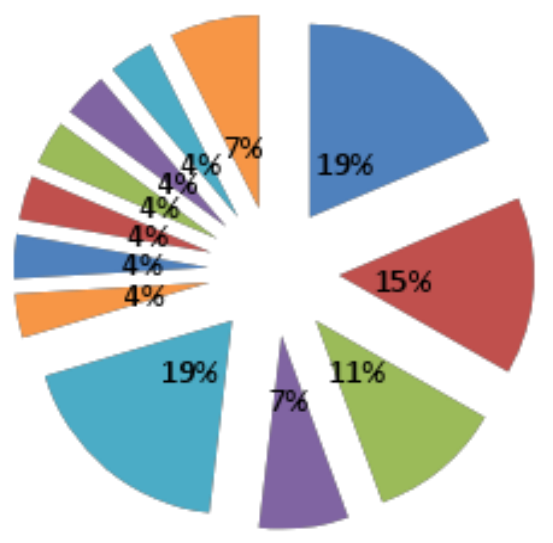

BARRA DO CHOÇA
PLANALTO
VITORIA DA CONQUISTA
PARAÍBA
PNAGÉ
ANARA DE SANTANA
FEITAPETINGA
CAATIBA
BOM J. DA SERRA
BEXEIRA DE FREITAS
TITAMARAJU
ITABUNA

Fonte: Trabalho de campo, 2016. Elaboração: Geisa Alves dos Santos.

A amostragem dos entrevistados equivalente a $30 \%$ da população total. A pesquisa revelou que $18 \%$ dos moradores são de origem da sede do municipal de Barra do Choça; $18 \%$ de Planalto e 15\% de Anagé, essas localidades destacadas são os munícipios que possuem um maior fluxo na localidade, seguidas de Caatiba, Feira de Santana e Paraíba, este ultimo corresponde a migração interestadual, cerca de $7 \%$ dos entrevistados são de origem Paraibana, um grupo de familiares relativamente grande que relatam morar a mais de 40 anos na localidade.

A partir do exposto, compreende-se que o ato de migrar para ambos os povoados foram semelhantes, as causas predominantes foram às condições climáticas e econômicas. Assim, é visto que a motivação dos migrantes era quase unanime, a fuga da seca e consequentemente uma vida melhor. As fixações de moradias permanentes culminam na atração de outras gerações de pessoas da mesma família, originando moradores nascidos nos povoados. 


\section{Aspectos populacionais atuais.}

Os povoados em questão são divididos em dois aglomerados de casas numa faixa territorial de distância de $1 \mathrm{~km}$. A população atual é composta por familiares que passam suas terras de pai para filhos, moradores antigos e recentes. O número de habitantes do Pov. I é menor do que o Pov. II, embora que o Pov. I tenha se originado primeiro.

A população do Pov. I é atualmente composta por 361 moradores seguidos de 523 moradores no Pov. II. A soma total dos dois aglomerados é de 884 pessoas residentes em 286 domícilios.

Percebe-se com os dados o adensamento de domicílios, no caso do Pov. II o número de habitantes é relativamente denso ao número de domicílios, ou seja, há um numero maior de pessoas convivendo no mesmo domicílio. Verificou-se, na pesquisa de campo, que a ocupação média dos imóveis é de quatro pessoas por residência. Já no Pov. I a média é de 2,7 pessoas por residência. Isso aponta que o maior número de habitantes no Pov. II não reflete no percentual de moradias.

O tempo de moradia também se difere, tendo em vista o Pov. I o maior núemero de moradores são com mais 40 anos de vivência no povoado, isso se deve a permanencia das gerações de familiares na localidade.

Figura 03- Gráfico com os dados do tempo de moradia dos moradores dos povoados.

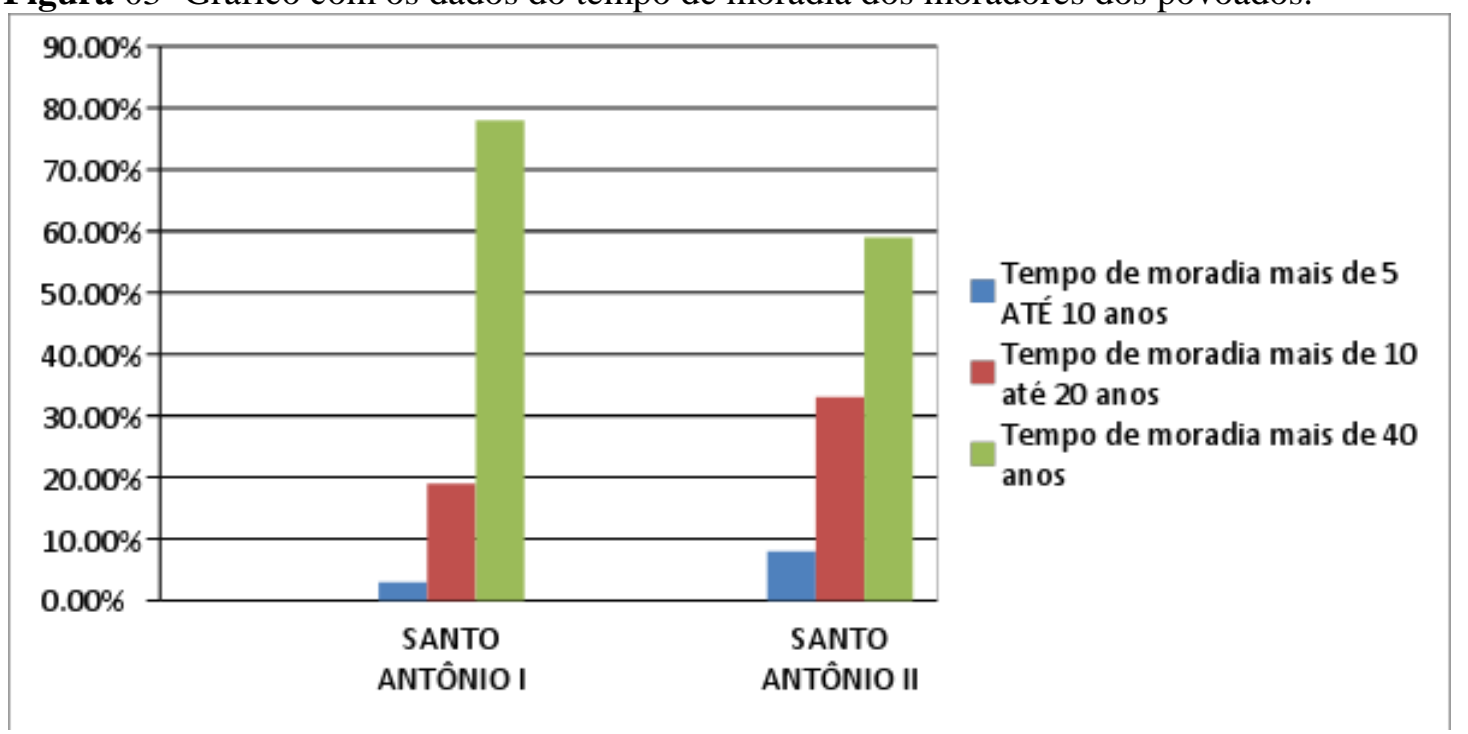

Fonte: Trabalho de campo, 2016. Elaboração: Geisa Alves dos Santos.

O gráfico aponta que $78 \%$ dos entrevistados residem no Pov. I a mais de 40 anos, já no Pov. II 59\% dos moradores possuem de 10 a 20 anos de tempo de moradia. Esses moradores entrevistados se encaixam nos fluxos migratórios que ocorreu na 
referida localidade no final da década de 1990 e inicio dos anos 2000, período este que, os dois aglomerados recebeu um número considerável de migrantes motivados pela colheita do café.

Percebe-se que nos últimos anos (de 5 a 10 anos) os povoados têm recebido novos moradores, em destaque o Pov. II em média 8\% de sua população chegante até a última década. Isso se deve a oferta de lotes na localidade, fora isso a disposição de casas para aluguéis, um fenômeno altamente urbano encontrado na localidade.

Além disso, outros dois tipos de migração são encontrados nos povoados: A migração de retorno ${ }^{6}$ e migração pendular. A migração de retorno se configra no processo de volta dos moradores originários dos povoados. De acordo com as entrevistas contatou-se que esse processo se deve especificamente de retorno do Estado de São Paulo.

Esse retorno se acentuou nos últimos 10 anos, dentre os motivos estão à questão familiar (morar perto dos parentes), situação de indentidade e pertecimento do lugar, outros relatam que moraram fora como o proposito de guardar dinheiro para construir casa nos povoados e se estabilizar financeiramente.

A migração pendular ${ }^{7}$ ocorre diariamente com o objetivo de trabalhar, estudar e executar outras atividades na cidade de Barra do Choça e sua hinterlândia. $\mathrm{O}$ acesso ao transporte seja de uso coletivo, privado e/ou público são elementos que facilitam esse movimento.

Verificou-se nos povoados estudantes que se deslocam de ônibus para as escolas, outros utlizam o transporte das vans para estudar em Vitória da Conquista. Em relação à mobilidade do trabalho, alguns moradores trabalham como pedreiro em Vitória da Conquista. Há também o deslocamento das trabalhadoras domésticas e comerciários para as cidades de Barra do Choça e Vitória da Conquista.

Os fluxos se intensificaram com a pavimentação asfaltica e implantação da rodovia BA 264 uma via de acesso que "corta" os povoados nos km 9 e 10 respectivamente. Assim "os fluxos são um resultado direto ou indireto das ações e atravessam ou se instalam nos fixos modificando a sua significação e seu valor, ao mesmo tempo em que também se modificam" (SANTOS, 1996, p.61).

\footnotetext{
${ }^{6}$ Para maior esclarecimento sobre o fenômeno da migração de retorno consultar a publicação da Revista International Journal on Multicultural Societies, v. 6, n. 2, 2004, p. 253-279 da autoria de Jean-Pierre Cassarino.

${ }^{7}$ O termo migração é comumente utilizado, mas vale lembrar que no Brasil a questão pendular ainda não foi reconhecida como migração, nas literaturas este tipo de deslocamento é tido como "movimento", pois só é considerado migração quando se estabelece moradia.
} 


\section{A dimâmica econômica dos povoados Santo Antônio I e II em Barra do Choça-Ba.}

Para compreender as atividades produtivas dos povoados e sua distribuição se faz necessário destacar esse processo na escala municipal. A economia do munícipio de Barra do Choça é centrada na lavoura cafeeira, que corresponde a $83 \%$ da atividade econômica e a maior parte da ocupação de mão de obra está voltada para essa atividade (SEI, 2015).

"A cafeicultura ganha força na região e eclodiu na década de 1970, alavancando a economia local" (ROCHA e SANTOS, 2015, p.17). Esses desdobramentos estão correlacionados com as atividades produtivas dos povoados em estudo, pois a produção cafeeira nessa localidade corresponde uma parcela significativa no PIB municipal ${ }^{8}$. Essas atividades econômicas compõe o setor primário da economia local bem como o comércio e serviços que se apresentam ainda tímidos que correspondem ao terceiro setor da economia.

Figura 04- Carta imagem com a estrutura produtiva do povoado de Santo Antônio-Barra do Choça-BA.

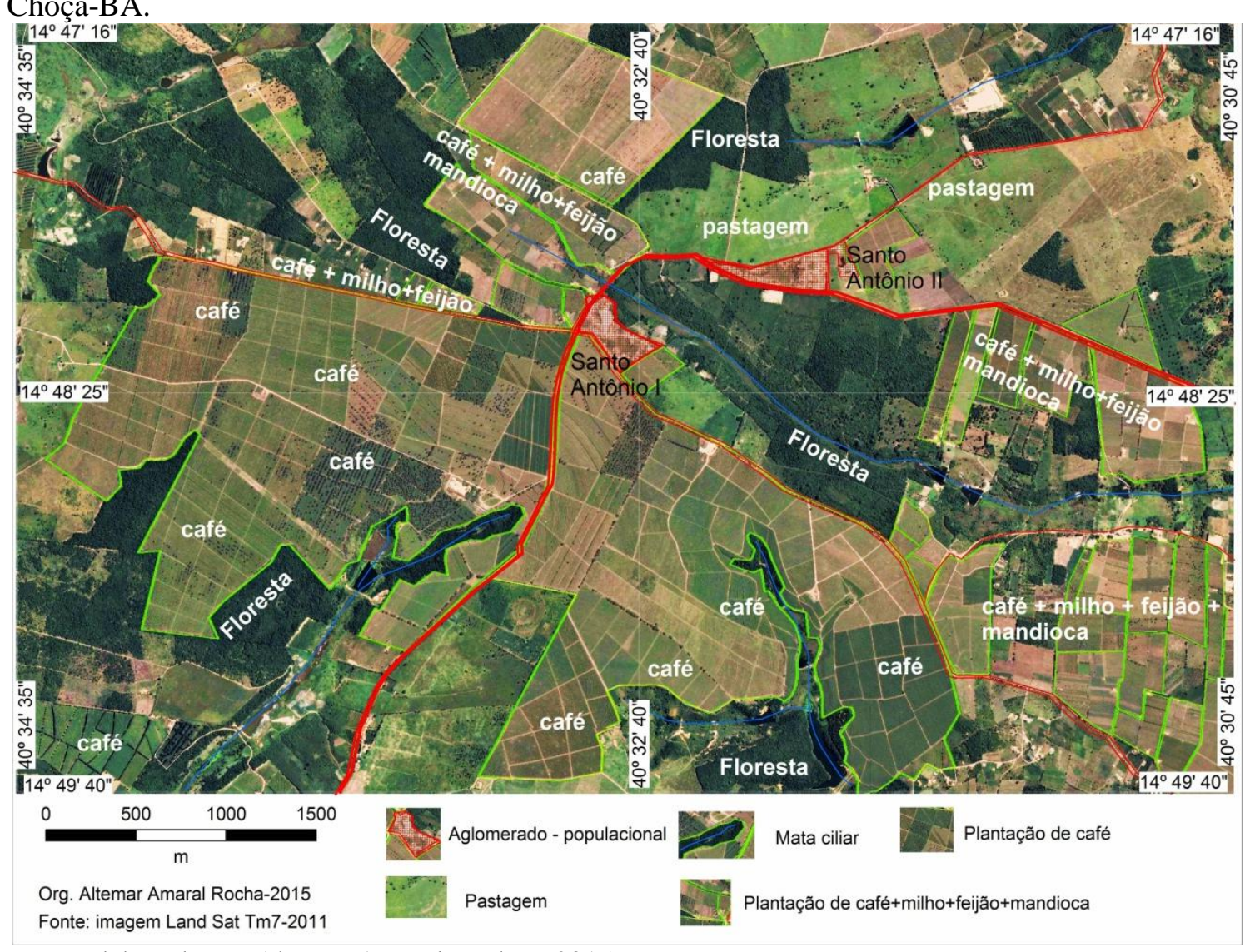

Fonte: elaborado por Altemar Amaral Rocha - 2015

A estrutura produtiva nos dois povoados em estudo é composta de grandes propriedades onde predominam a cafeicultura e pequenas propriedades de agricultores

\footnotetext{
${ }^{8}$ Essa distribuição do PIB (Produto Interno Bruto) do munícipio se encontra nos dados da SEI/IBGE(2015).
} 
familiares que trabalham na lavoura de feijão, milho e mandioca. $\mathrm{O}$ investimento na cafeicultura inseriu o município no circuito cafeeiro nacional (SEI, 2015). Das 12.960 toneladas de café produzidas em 2013 no município de Barra do Choça, 15\% foram produzidas no entorno dos Povoados de Santo Antônio I e II. (ROCHA e SANTOS, 2015, p.17).

As plantações de mandioca, milho e feijão correspondem a pequenas propriedades, o que corroboram a agricultura de subsistência. Foi verificada através do trabalho de campo que a maior parte das lavouras é destinada para o consumo familiar e quem trabalha nessas lavouras são os próprios familiares sem uma divisão nitída do trabalho, com poucos recursos e tecnoligia escassa. A produção de pequena escala não gera lucro a ponto de contratar um funcionário para auxiliar nas atividades.

Em relação à agricultura comercial, verificou que apenas uma pequena parte das lavouras são comercializadas na feira livre na cidade de Barra do Choça. Um tipo comum de comércio praticado pelos pequenos agricultores é feitos pelos atravessadores, uma espécie de mascates nas lavouras, eles se deslocam nas propriedades e compram os produtos para revender no $\mathrm{CEASA}^{9}$ em Vitória da Conquista.

A forma de vender os produtos para os atravessadores é tida como pratico pelos donos das lavouras, eles justifica isso como contenção de gastos, conforme foi explanado pela entrevistada Dona E. "eles vem comprar direto aqui na roça, é bom que nois não precisa ir em Conquista, já livra o frete dos produtos e os atravessadores pagam na hora, livrando a gente do transtorno de vender no CEASA". (Informação verbal, 2016). Nas palavras da entrevistada esse modo de comercialização é visto como algo bom e proveitoso para os donos de lavoura. No entanto, observou-se que os valores pagos pelos atravessadores ficam aquém do valor de mercado, mesmo com os gastos de deslocamento seria mais lucrativo para o agricultor fazer a mediação diretamente com o CEASA.

Por outro lado, a lavoura de café produzida em sua maioria pelas grandes fazendas nos arredores dos povoados é responsável pelo maior número de empregados da localidade no período de safra e entressafra. O período da safra é a colheita do café ocorre principalmente de maio a julho, gerando trabalho e renda para a população não somente dos povoados, mas também da cidade. O problema é que essa modalidade gera apenas empregos temporários, isso gera uma instabilidade financeira para grande parte dos trabalhadores.

\footnotetext{
${ }^{9}$ Centro de Abastecimento de Vitória da conquista, principal centro que abastece os munícipios da região sudoeste.
} 
Constatou-se também que um dos motivos da safra dos últimos anos ter diminuído a contratação de mão de obra na colheita se deve a inserção da "maquinização" na colheita do café. Esse processo se deve a modernização da agricultura brasileira na contemporaneidade, conforme Santos (1996) as transformações sejam no campo ou na cidade, são decorrentes das forças hegemônicas capitalistas, como um aspecto predominante do meio técnico- cientifico-informacional.

Nesse caso, a inserção da maquina colheitadeira de café diminui a contratação da mão de obra e com isso aumenta o lucro e produtividade. O esquema a seguir define como ocorre esse processo.

Quadro I - Máquina X Catador: O uso da maquinização para aumento de lucro e produtividade nos povoados.

\begin{tabular}{|c|c|c|c|}
\hline $\begin{array}{c}\text { Modo de colheita do } \\
\text { café }\end{array}$ & $\begin{array}{c}\text { Período de colheita } \\
\text { diária }\end{array}$ & Latas de café colhidas & Custo da lata de café \\
\hline Máquina Agrícola & $22 \mathrm{HS}$ & 2860 & $\mathrm{R} \$ 0,50$ \\
\hline $\begin{array}{c}\text { Trabalhador/ Catador de } \\
\text { café }\end{array}$ & $08 \mathrm{HS}$ & 30 & $\mathrm{R} \$ 3,00$ \\
\hline
\end{tabular}

Fonte: Trabalho de campo, 2016. Elaboração: Geisa Alves dos Santos.

Esses dados do quadro ${ }^{10}$ comprovam que no quesito lucro é vantajoso para os fazendeiros colherem o café com o uso das máquinas, visto que uma única máquina realiza o trabalho equivalente a 100 pessoas diariamente, além da maior produtividade o custo final é muito menor, enquanto o fazendeiro realiza o pagamento de em média $\mathrm{R} \$$ 3,00 para o trabalhador em cada lata colhida, com a máquina aproximadamente $\mathrm{R} \$ 0,50$ centavos na lata.

Com a colheita manual a fazenda emprega diretamente 10 pessoas distribuídas nas tarefas de "cabo de turma" (fiscal), aferidor de medidas das latas, tratorista para carregar o café e liberador de fichas (um papel marcando o número de latas que será trocado por dinheiro no dia do pagamento). Por outro lado, o custo final da máquina colheitadeira é de R \$ 0,50 centavos por lata de café colhida, nesse valor já está incluso o gasto com o tratorista, maquinista e o óleo. Assim, a colheita manual emprega em média 10 pessoas diretamente e a colheita industrial emprega apenas 02 pessoas.

Em contrapartida, a máquina danifica o pé de café, pois o processo mecanizado agride diretamente a planta. A colheita com o uso da máquina só é feito do modo de tirar todo o café do pé. Dessa forma, em curto prazo a máquina gera maior

\footnotetext{
${ }^{10}$ Os dados do quadro foram feitos a partir de entrevistas nas fazendas locais e os números expressos são da última safra nas referidas fazendas.
} 
produtividade e lucro, mas em longo prazo pode danificar a lavoura impedindo a safra do ano seguinte.

De todo o modo, o trabalhador é imprescindível na colheita do café, pois o processo de catar o café só é feito com a mão de obra humana e este ainda é o meio mais saudável para a permanência da lavoura e do homem no campo.

Outro fator vem se destacando nos últimos anos é a diminuição da produtividade nas safras. Isso foi atribuído, pelos grandes produtores de café devido, as mudanças climáticas ocorridas na região do Sudoeste baiano que predominava um clima propício para o cultivo cafeeiro sendo o munícipio de Barra do Choça conhecido como a "terra do café".

Nos últimos cinco anos um período de forte estiagem afetou diretamente a produção. O que acarretou na diminuição dos postos de trabalho e como a economia municipal é voltado para a produção do café uma crise de desemprego se instaura.

Contudo, apesar dos problemas envolvendo a atividade cafeeira, é notório que,

A inserção da cafeicultura provocou mudanças no contexto produtivo e por consequência na configuração do meio rural e do modo de vida dos trabalhadores. Já que se estabelecem novas relações e com isso ampliam-se as redes de influencia no cenário regional. (ROCHA e SANTOS, 2015, p.18).

Isso justifica a permanência de muitos moradores que vieram trabalhar no período de colheita do café e fixaram morada.

Apesar dos infortúnios a produção, "o beneficiamento e a exportação do café continuam a ser a principal fonte de renda da população direta ou indiretamente ligada à cadeia produtiva da cafeicultura”. (ROCHA e SANTOS, 2015, p.18).

A situação do desemprego e da baixa produtividade do café gerou um fenômeno novo nos últimos anos no município de Barra do Choça. O município que até então era receptor de migrantes para trabalhar na colheita hoje é emissor de trabalhadores para a colheita do café em outras localidades. Esse processo geograficamente denominado de migração sazonal ocorre em curtos períodos do ano, uma situação que faz parte da realidade dos moradores dos povoados Santo Antônio I e II há uma década. A migração sazonal tem como destino grandes fazendas em Ibiraci próximo a Franca no estado de Minas Gerais e "Bruno" e "Domingão" no Espírito Santo".

\footnotetext{
${ }^{11}$ Conforme entrevista dos trabalhadores, estes por sua vez só sabem os nomes das fazendas "bruno" e "Domingão", mas não sabem dizer em qual munícipio estas são localizadas no Espiríto Santo.
} 
Com base nas entrevistas, observou que o primeiro grupo de trabalhadores que se deslocaram dos povoados para a atividade supracitada foi no ano de 2007. A partir de então, os anos seguintes foram marcados pelo aumento de saída destes trabalhadores.

Segundo o trabalhador entrevistado o ano de 2012 foi o mais rentável e serviu de estímulo para aumentar o número de trabalhadores, "foi o ano que o povo mais ganhou dinheiro, foi exemplo pro povo animar e ir no próximo ano". Quando perguntado sobre quanto seria essa quantia ele respondeu "dependo da pessoa em dois meses dá pra tirar uns R\$ 4.000,00 reais". (informação verbal, 2017). O trabalhador entrevistado se refere a uma fazenda localizada em Minas Gerais. No ano de 2013 saíram dos dois povoados em média 30 homens entre jovens e adultos.

Ficou constatado que a quantia declarada como pagamento pelo trabalho é muito maior do que no seu local de origem, no entanto, as condições de trabalho, moradia e alimentação são bem precárias. Os catadores de café trabalham geralmente de segunda à domingo das 05 da manhã às 18:00 horas, exceto no domingo que trabalham até meiodia. Alguns trabalhadores alegaram que a única forma de conseguir acumular dinheiro é trabalhando até a exaustão, como afirma o entrevistado $\mathrm{Y}$ "a gente aproveita que o café tá bom e se mata de trabalhar, pra juntar dinheiro à gente tira energia de onde não tem" (Informação verbal, 2016). Diante do exposto, entende-se que essa saída temporária se deve a diminuição da produção de café e a inserção de novas tecnologias no processo produtivo.

\section{Setor terciário da economia local}

O comércio e serviços que compõe o setor teciário contribuem com a composição da economia local. Nos povoados ocorrem de forma tímida, mas relevante. Este setor é responsável, em grande, parte pelo fluxo de pessoas, ou seja, se há circulação de pessoas, circula a mercadoria, dinheiro, informação e consequentemente movimenta a economia do lugar.

Os povoados dispõem de estabelecimentos de produtos alimentícios em geral como: os mercadinhos e mercearia. Além disso, destacam-se bares e lanchonete que são utilizados como objeto de lazer pelos moradores. Os serviços mais específicos tais como: loja de peças de motos, material de construção, salão de beleza e etc.

Esses estabelecimentos são comandados pelos próprios donos com o apoio da mão de obra familiar, muito comum em localidades menores. Dessa forma, dos entrevistados, amostra de 30 famílias (das 133 exixtentes no Pov. I), constatou-se que 
$100 \%$ realizam suas compras do dia a dia na referida localidade, já no Pov. II das 35 famílias entrevistadas, no total de 153 famílias existentes, verificou-se que $43 \%$ realizam compras diárias no local e $47 \%$ faz essas compras no Pov. I. Esse deslocamento se deve a maior variedade de produtos e melhores preços.

Esses dados comprovam que os moradores destes povoados não precisam se deslocar até a cidade de Barra do Choça para fazer compras do dia a dia ou realizar funções básicas, o que corrobora nas relações de complementariedade da economia local.

\section{Aspectos que qualificam as condições de vida dos moradores dos Povoados Santo Antônio I e II.}

As condições de vida de uma população são norteadas na geografia por meio dos “indicadores sociais" que contemplam os aspectos populacionais, econômico, educação, saúde, trabalho e renda, habitação e saneamento básico. Assim, para relatar as condições de vida dos moradores dos Pov. I e II essa pesquisa analisou as condição de vida desses indivíduos como: Habitação, saneamento básico e renda;

As condições de moradia é um aspecto que corrobora os demais indicadores, pois "há o entendimento de que "viver com dignidade" exige que um conjunto de situações ocorra simultaneamente. A casa é o elemento nodal e em seu entorno é onde se instalam os serviços". (IBGE, 2013, p.78), ou seja, as casas simboliza o primeiro passo para "viver bem".

Verificou-se que as casas dos povoados podem ser caracterizadas como boa e até ótima no que se refere aos tipos de moradia e estrutura física. ${ }^{12}$ Dos 286 domicílios nos dois aglomerados constatou-se que 284 são estruturadas em alvenaria (blocos e adobes), e 02 domicílios de pau-a-pique (casas com estrutura de barro, amarrada por varas). ${ }^{13}$ No que se refere ao interior das casas mais de $80 \%$ possui cimento liso ou cerâmica, $60 \%$ das casas são forradas.

Um aspecto predominantemente urbano é visto na maior parte das casas que são os muros. Uma estrutura que até então predominava nas cidades "invadiu” as habitações dos povoados, isso se deve ao modo de vida urbano atrelado ao subespaço rural que representa o território dos povoados.

\footnotetext{
${ }^{12}$ Esses dados foram obitidos mediante a aplicação de questionários e a interpretação se deve a observação direta de campo.

${ }^{13}$ Em sua maioria a alvenaria ou estrutura da casa é feita por blocos ou metade adobe/bloco, o pau-a-pique era o tipo de casa mais comum nas localidades, um tipo barato e construído pelos próprios moradores que com o passar do tempo com as melhorias na condição de vida foram construindo casas mais aconchegantes.
} 
A habitação é relacionada com o saneamento básico pelo fato deste ser um conjunto de serviços que devem ser prestados aos domicílios. O sistema de abastecimento de água, por rede geral, é fornecido para a totalidade de domicílios sendo de responsabilidade da Empresa Baiana de Saneamento-EMBASA. Entretanto verificou-se que mesmo atendidos pelo abastecimento via rede geral, uma pequena parcela de moradores ainda utilizam a cisterna como alternativa caso falte água encanada. Inclui também a iluminação elétrica como um serviço ao domicílio, que atende também $100 \%$ dos moradores, esta de responsabilidade da Companhia Elétrica da Bahia - COELBA.

Figura 05- Painel dos tipos de moradias existentes nos povoados.

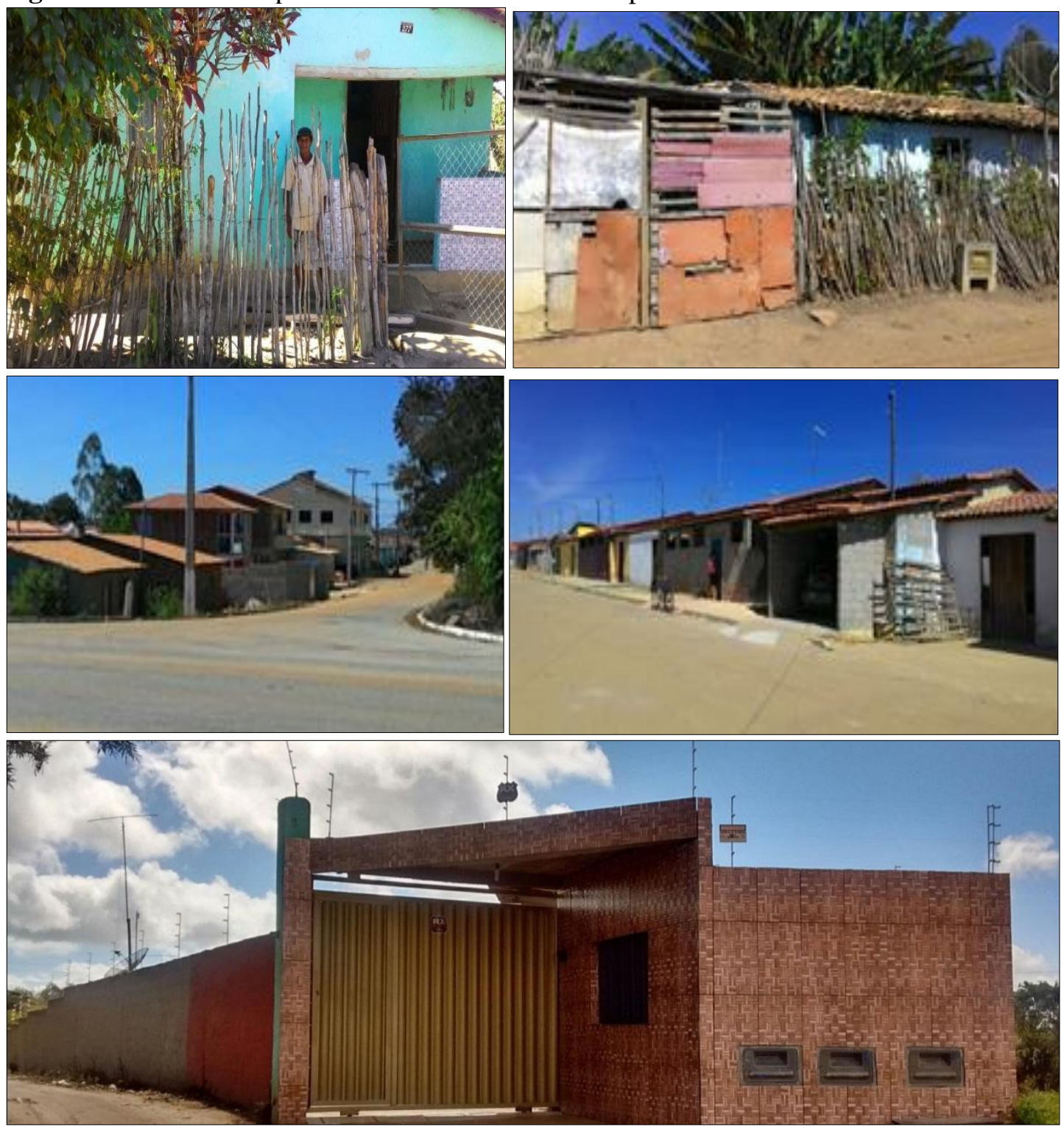

Fonte: Trabalho de campo, 2017.

No que se refere à disposição final dos dejetos sólidos, ou seja, o destino final do lixo destaca-se que o descarte do lixo é feito semanalmente por meio da coleta realizada 
pela prefeitura no "caminhão do lixo" como relatado pelos moradores sempre na terçafeira.

Em contrapartida, observou-se que é inexistente o sistema de esgotamento sanitário e $100 \%$ dos moradores utilizam a fossa séptica. Contudo, é visto que em alguns lugares os dejetos são lançados a céu aberto (Figura 06).

Figura 06- Imagens de dejetos sanitários lançados diretamente na rua nos povoados.

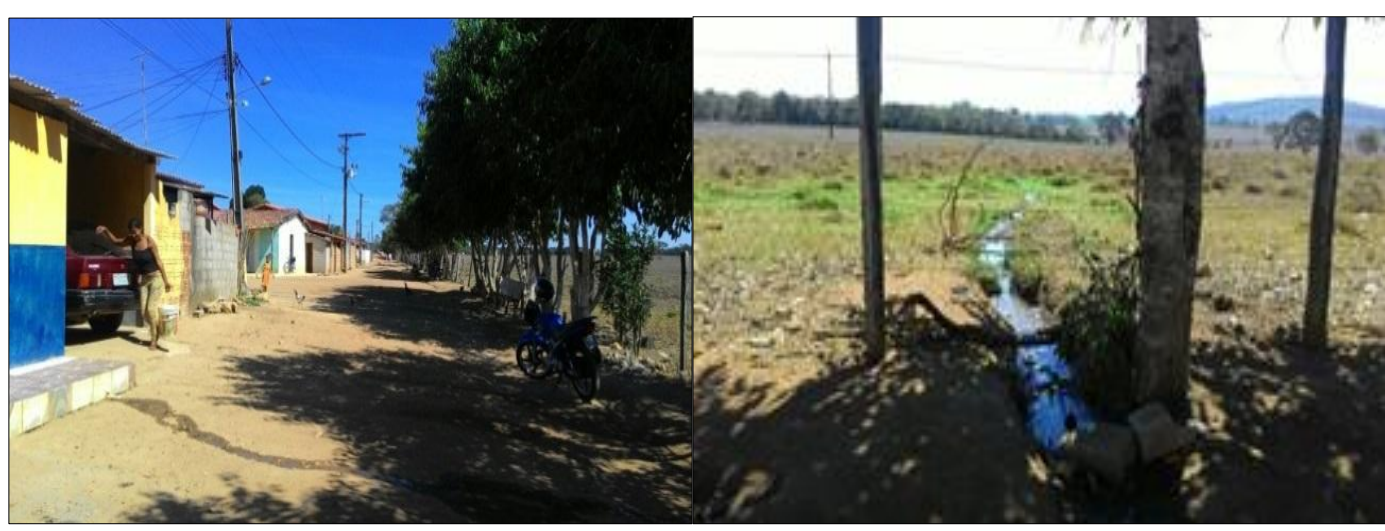

Fonte: Trabalho de campo, 2017.

O descarte de dejetos a céu aberto é um aspecto negativo na condição de vida dos moradores, pois, a disposição inadequada compromete a da saúde pública, principalmente das crianças que brincam na rua, expostas a doenças. Além disso, compromete a preservação do meio ambiente. Por isso, esse fator é um grande descontentamento da população local que alega não ter espaços no quintal para fazer a fossa séptica.

Nesse contexto, averiguou que $90 \%$ dos domicílios dos dois povoados dispõem de banheiros no interior da casa, $5 \%$ possuem banheiros na parte externa da moradia e outros $5 \%$ não tem banheiros. Dos domicílios que não tem banheiro os moradores improvisam banheiros de lonas, panos de café na parte externa da casa o que representa um risco potencial para propagação de doenças.

Outro indicador que caracteriza as condições de vida dos moradores é a renda, seja ela oriunda de trabalho de carteira assinada, informal ou mediante á proteção social que é a aposentadoria e outros benefícios da previdência social e benefícios de transferência de renda de cunho assistencialista, principalmente o Programa Bolsa família.

Identificou-se que a renda dos entrevistados no Pov. I não ultrapassa mais de dois salários mínimos. Dos 361 moradores 56 recebem a aposentadoria, assim do total de $100 \%$ dos indivíduos $15,5 \%$ são aposentados. No caso do Bolsa Família, do total de 133 domicílios, 45 recebem o benefício, correspondente a 33,8\%. Sobre a renda de 
quem trabalha com carteira assinada, dos 30 entrevistados, um total de 10 trabalha de carteira assinada e possui a renda de um salário mínimo, ou seja, 15,3\% da população entrevistada; a renda do trabalhador informal compete à maioria da renda dos entrevistados 56,4\% declaram trabalhar sem carteira assinada dispondo de uma renda de um a dois salários mínimos.

No caso do Pov. II a situação não se difere muito. Dos 523 moradores, 86 destes recebem a aposentadoria, assim do total de $100 \%$ apenas $16,5 \%$ são aposentados. O benefício Bolsa Família atende uma parcela significativa dos moradores visto que dos 153 domicílios cerca de 100 recebem o benefício, corresponde a 65,5\% das famílias. Esse benefício contribui coma dinâmica econômica dos povoados.

Sobre a renda de quem trabalha com carteira assinada dos 35 entrevistados um total de 10 trabalha de carteira assinada e possui a renda de um salário mínimo, ou seja, $28,5 \%$ da população entrevistada; a renda do trabalhador informal compete à maioria da renda dos entrevistados $71,5 \%$ declaram trabalhar sem carteira assinada dispondo de uma renda de um a dois salários mínimos.

De modo geral, o acesso às politicas publica são necessárias para a valorização da vida em sociedade bem como recursos para melhorias nas localidades, mas, pouca coisa foi feita. Os moradores relataram que estão à espera de uma praça e uma quadra poliesportiva prometida há quase 15 anos. No lugar que seria implementada a praça serve como quadra improvisada e também sedia eventos, embora não haja nenhuma infraestrutura ou bemfeitoria no espaço.

A falta de calçamento nas ruas é também um ponto negativo na condição de vida. No período chuvoso a inscindência é a lama no periodo de sol a população sofre com a poeira. A quantidade de buraocos reduz a mobilidadeou até mesmo o acesso em algumas áreas. Além disso, após a chuva surgem crateras que dificultam a passagem dos veículos principalmente os de pequeno porte. Diante do exposto, os moradores estão insatisfeitos com a falta de políticas publicas nos povoados.

Recentemente, com o intuito de trazer benefícios e acesso a politicas públicas para melhorar as condições de vida nos povoados um grupo de moradores criaram uma associação, cujo objetivo é captar recursos públicos . A associação dos Moradores do Povoado Santo Antônio - AMPOSA. Ainda está em fase embrionária, mas já é o inicio de uma mobilização popular da sociedade em busca do bem comum.

\section{Considerações finais}


Pode-se afirmar que a existência dos povoados Santo Antônio I e II está diretamente ligada ao município de Barra do Choça - BA desde o período da formação territorial. Está também relacionada à instalação de um fixo, a estrada que liga Barra a Planalto e a interesses capitalistas, visto que o aglomerado surge da necessidade de manter os trabalhadores próximos às fazendas de café da região.

A dinâmica do território nos povoados está ligada ao modo de vida rural principalmente no que se refere ao trabalho. O setor primário tem grande expressividade, o secundário não existe, e o terciário tem uma participação pequena, mas de suma importância nas relações de complementariedade entre os povoados. As atividades econômicas são voltadas para a produção, o beneficiamento e a exportação do café que juntos continuam a ser a principal fonte de renda da população direta ou indiretamente ligada ao circuito produtivo do café.

No que se refere às condições de vida da população a maior parte tem renda familiar de um a dois salários mínimos, boa parte não possui emprego formal e a maioria dos moradores é assistida pelo programa Bolsa Família. Na realidade, essa é uma das poucas ações de política pública que chega a população. Quando falamos em Bolsa família abordamos uma questão delicada por dois motivos: o primeiro é um ponto positivo, pois demostra que muitas famílias são assistidas por programas sociais o segundo é que indica a baixa remuneração, a presença de empregos informais ou formais, mas mal remunerados. Pois para ter acesso ao benefício o candidato deve estar em situação de pobreza.

Apesar dessas considerações de modo geral as moradias são boas, com alvenarias, forros, piso e banheiro dentro das casas. As residências são abastecidas com água e energia, bens inestimáveis para o acesso a cidadania. Embora, ainda seja inesistente o calçamento das ruas e melhor preservação do meio ambiente.

O acesso à saúde e educação é bem visto pela maioria da população, porém faz necessário efetuar deslocamento para Barra do Choça e/ou Vitória da Conquista a fim de obter um tratamento de saúde ou definir a vida profissional com um curso profissionalizante ou superior.

Dentre os elementos estudados o fator que confere maior dinamicidade ao território é a cafeicultura. Essa atividade é responsável por: injetar dinheiro nos povoados o que movimenta o comércio local, atrair trabalhadores para outros estados como Minas Gerais e Espirito Santo de forma sazonal, atrair trabalhadores de cidades 
vizinhas para os povoados e gerar trabalho, mesmo que precário, e renda para uma parte significativa da população.

Este estudo apresentou dois povoados em suas formas e conteúdos, articulados pela dinâmica do território. Quando os homens agem sobre o território e dele se apropriam conferem vida aquela fração do espaço e faz dele seu abrigo.

\section{Referências}

CANDIOTTO, L.Z .P; CORRÊA, W.K. Ruralidades, urbanidades e a tecnicização do rural no contexto do debate cidade-campo. In: Campo-território: revista de geografia agrária, São Pualo v.3, n. 5, p. 214-242, fev. 2008.

DAMIANI, Amélia. Geografia e população. São Paulo: Editora contexto, 2002.

GOMES, R. A. A vila da Barra, sua passagem à Distrito e Emancipação Política (1910 a 1962). Monografia de Graduação em História. UESB, Vitória da Conquista, 2008.

IBGE. Censo demográfico 2010. Rio de Janeiro: IBGE. 2011, Disponível em: http://www.sidra.ibge.gov.br/cd/cd2010universo.asp?o=7\&i=P .Acesso em: 02 /04/2016.

Censo demográfico, series temporais: Rio de Janeiro: IBGE.2011, disponível em: http://www.sidra.ibge.gov.br/cd/cd2010Serie.asp?o=2\&i=P, Acesso em: 02 de abril de 2016.

ROCHA, A.A; SANTOS, A.G. A dimensão do urbano e as relações de produção no povoado Santo Antônio- Barra do Choça-BA. Anais XIV Simpósio Nacional de Geografia Urbana, Fortaleza, 2015.

SANTOS, Milton. A Natureza do Espaço. Técnica e Tempo. Razão e Emoção. São Paulo, Hucitec, 1996. (3 $3^{a}$ edição: 1999)

A Urbanização Brasileira, São Paulo,Hucitec, 1993, (4ª edição: 1998).

VALVERDE, R.R.H. Transformações no conceito de território: competição e mobilidade na cidade. In: GEOUSP - Espaço e Tempo, São Paulo, São Paulo, No 15, pp. 119 - 126, 2004.

Recebido em: 18/11/2017

Aceito para publicação em: 10/12/2017 